\title{
Soundbites and patient centred care
}

1. Paul Dieppe, director,

2. Rob Horne, director

Former prime minister Harold Macmillan famously once said, "You've never had it so good," thereby inventing a classic soundbite. It could be argued that health care has never had it so good—we are enjoying access to an unprecedented range of powerful and effective means of combating disease and illness; we are living longer, healthier lives; and spending on health care has never been so high. However, expectations have risen faster than improved healthcare delivery, which has resulted in major political and financial pressures on the NHS, and mounting public dissatisfaction. There is concern, too, that health professionals remain too aloof, paternalistic, and controlling to suit the needs of their patients. We need more "patient centred health care," it is claimed.

\section{The simplicity of the soundbite may obscure the complexity of the issue}

The government has responded actively to this concern. Over the past few years it has introduced several high profile initiatives designed to give patients more control over their health care, and to reduce the paternalistic attitudes of health professionals. Most of these initiatives are characterised by a soundbite. Examples include "integrated medicine," "shared decision making," "empowerment," "informed choice," "dignity in health care," "concordance," and "the expert patient." We believe that soundbite initiatives are a double edged sword: they can result in both good and bad outcomes.

Soundbites can be valuable if they help make a complex concept seem simple and obvious_for example, "free health care at the point of delivery." However, the simplicity of the soundbite brings with it the first problem-the fact that it may obscure the complexity of the issue (does anyone understand what "action research" really means?). The idea of promoting patient centred health care has an immediate appeal—we can all see that health care should be centred on the needs of the individual patient. However, what does this actually mean, and how is it to be achieved?

To be effective, initiatives need to change behaviour. The numerous initiatives and soundbites listed above have had the positive effect of cautioning against health care that is too paternalistic and highlighting the central importance of patients' perspectives of illness and treatment. This might create a warm glow but this is not enough. Initiatives need to help us understand why, when, and how we should change our behaviour and how such changes might lead to improved health outcomes. In the era of evidence based health care we should also ensure that the initiatives we promote and spend money on are guided by a sound theoretical and evidence base. Moreover, we need to consider whether such initiatives are likely to be inclusive or merely tend to perpetuate the current inequalities of access to and take up of healthcare services. We are concerned that many aspects of the patient centred health care movement are inaccessible to the most disadvantaged people in our society. As a bare minimum these initiatives should mean something to people who have not read Kafka.

Before any soundbite is turned into an initiative, several questions should be asked or criteria applied. Firstly, we need to be clear about what the soundbite means. It is rarely apparent whether we are talking about something 
that is considered an "on-off" concept or a graded one (can dignity only be present or absent, or is it a graded variable, for example?). Similarly, is it a process related concept or does it pertain to outcome? Does it differ from any of the other words and concepts used in the past, and, if not, is it of any use? What would we achieve if we acted on it, and how would we know when we had got there? Does it have a good theoretical basis to justify its introduction, and can it be measured and assessed? Who is it for-the patients or the professionals?

We suggest that these questions are examined carefully before putting more money into such initiatives. Failure to develop a clear working definition of any new construct can lead to confusion. There is a risk that a concept that is clear to its originators may be misinterpreted and inappropriately used by its target audience. The inappropriate replacement of the words compliance or adherence with concordance may be one such example. We live in an age of accountability and evidence based medicine; we should take as critical and scholarly an approach to initiatives and soundbites surrounding patient centred health care as we do to any other aspect of our work in health care. Political correctness is not enough.

Finally, it seems to us that all of the initiatives surrounding the concept of patient centred care are concerned with the central feature of all health care that never seems to get mentioned-communication between the patient and the professional. Perhaps they can all be collapsed into one simple idea-that we need to improve the ways in which professionals and patients communicate with each other. 